\title{
Contemporary Social Work Practice with Veterans: An Introduction to the Special Issue
}

\author{
Katharine Bloeser ${ }^{1}$ (1) $\cdot$ Kathleen Ray $^{2}$
}

Published online: 2 May 2018

○) Springer Science+Business Media, LLC, part of Springer Nature 2018

\begin{abstract}
This special issue is a historical marker for contemporary social work practice with veteran populations. The editors requested papers from private, public, and academic settings that illustrate the special needs of veterans. The articles in this issue address the impact of military culture and the veteran identity, diversity, eras of service, access to care, and different stages psycho-social development on clinical practice. This introduction places the articles submitted in the context of historical and current trends in veterans' research concluding with a call to recognize resilience inherent in this population. It is hoped that this issue will serve as a tool for clinicians, researchers, and educators to improve upon their work as well as bring a new generation to serve and support those who served.
\end{abstract}

Keywords Veterans $\cdot$ Social work $\cdot$ Clinical social work $\cdot$ Contemporary practice

\section{Introduction}

This special issue of the Clinical Social Work Journal focusses on the topic of veterans and their clinical care. This topic was suggested by the authors as they both moved from working at the US Department of Veterans Affairs (VA) to academia and found students increasingly interested in learning about veteran care and conference and continuing education presentation attendees included non-VA social workers. Our goal for this special issue is to highlight issues within and examples of contemporary social work practice with veteran populations. Here, our definition of veteran was an individual who has retired from, deployed with, or is no longer Active Duty in the US military. We sought to gather a volume of work that could speak to practitioners in community agencies, academia, and government. The manuscripts submitted represent the diversity of social work practice in these settings and address concerns of special populations.

Katharine Bloeser

Kb1568@hunter.cuny.edu

1 Silberman School of Social Work at Hunter College, City University of New York, 2180 Third Avenue, New York, NY 10035, USA

2 School of Social Science and Human Services, Ramapo College of New Jersey, 505 Ramapo Valley Road, Mahwah, NJ 07430, USA
This special issue reflects the diversity of practice with veteran populations. Social workers within the Veterans Health Administration (VHA) report a variety of practice areas. In a survey of VA social workers, the majority (63\%) had worked in the VA 0-5 years, identified as female (vs. male, $74 \%$ ), and had veterans in their families (70\%). Onethird of VA social workers report work in case management, with an additional $35 \%$ in behavioral health, $12 \%$ in medical or surgical units, $8 \%$ in PTSD clinics, $7 \%$ in administration, and 3\% in TBI units (Beder and Postiglione 2013). Currently, only $37 \%$ of all veterans are enrolled at the VA (Kizer 2012), which means the majority of their care is being performed in the community. Social workers in the private sector are performing many of these same clinical duties outside VHA yet lack specialized training or knowledge regarding the veteran experience. It is also likely that more medical and behavioral health care will be provided in the private sector as the current presidential administration seeks to privatize some aspects of VA care.

Many veterans may not feel comfortable with the military or government association of the VA (Saha et al. 2008). They may have other forms of health insurance including private insurance or Medicare (Hynes et al. 2007) or may not qualify for VA care (Kizer 2012). There is a documented gap in providers' knowledge about veterans. In one survey of mental health clinicians ( $60 \%$ of whom were social workers), respondents reported minimal knowledge regarding the 
treatment of veterans in the area of military sexual trauma (57\%) and pain management $(50 \%)$. Yet more providers reported minimal confidence in treatment of military sexual trauma (58\%), pain management (59\%), sleep disorders (52\%), and traumatic brain injury (TBI; 63\%; Koblinsky et al. 2014). We hope this special issue will serve as a first step for many to learn more about this area of practice and will join the canon of literature already published in social work practice with veterans.

\section{Who are America's Veterans?}

When asked to envision a veteran we often think of the service member returning home from Afghanistan or Iraq with posttraumatic stress disorder (PTSD) or a traumatic brain injury (TBI). Perhaps we envision a homeless person we passed with a sign indicating they are a veteran. Or we picture and older person proudly wearing a Vietnam, Korean, or World War II hat-navy blue with corresponding ribbons. The reality is that as a group, veterans are as diverse as the nation they served. Veterans do share a unique culture, one that may intersect with other identities including race, gender, and sexual orientation. This special issue includes a discussion of military cultural competence from Hazel Atuel and Carl Castro. The authors discuss military culture and identity and present the clinical applications of the military experience. Also included is "Using Two Intersubjective Perspectives in Combat Deployment: A Military Mental Health Professional's Experience" where a veteran discusses their role as a provider and fellow veteran and how these two identities contribute to the therapeutic relationship and how the provider learned from their client about work in non-traditional clinical settings.

\section{Diversity}

Racial and ethnic diversity among veterans is growing over time (Oddone et al. 2002) making the World War II generation different from the Global War on Terror generation. According to data from the 2014 US Census Bureau, 22\% of all veterans identify as non-White. Eleven percent of veterans identify as Black and 7\% identify as Hispanic. Among female veterans, one-third identify as non-White, including $18 \%$ who identify as Black and $8 \%$ as Hispanic (National Center for Veterans Analysis and Statistics 2016). The number of women in the veteran population has also grown and identification as transgender is more likely in veteran populations. About $9 \%$ of the total veteran population are women (National Center for Veterans Analysis and Statistics 2016). In the VA healthcare system, the prevalence of identifying as transgender is significantly higher than in the general population. Research suggests that the prevalence of gender identity disorder in VA records is 22.9 per 100,000 in comparison to the general US population prevalence of 4.3 per 100,000 (Blosnich et al. 2013).

Unfortunately, veterans face many of the same effects of structural racism, sexism, and heterosexism as their nonveteran counterparts making work with this population close to social work's mission. Even with the assumption of equal access to care, veterans who identify as racial/ethnic minorities face treatment disparities for ischemic heart disease, cerebral vascular disease, mental health disorders (Oddone et al. 2002), arthritis, cancer, diabetes, preventive care, HIV and Hepatitis C, and rehabilitation and palliative care (Saha et al. 2008). Female veterans age 35 and older have a lower median household income than male veterans and $12 \%$ of female veterans report using the Supplemental Nutrition Assistance Program in comparison to 6\% of male veterans (National Center for Veterans Analysis and Statistics 2016). While VA has been able to virtually eliminate gender disparities between men and women in screening for PTSD and depression, differences persist in cholesterol management for veterans with ischemic heart disease and diabetes (Whitehead et al. 2014). Veterans who identify as transgender have a rate of suicide related behaviors including attempts, gestures, and plans that is $20 \times$ that of the general VA using population (Blosnich et al. 2013). The effects of these social determinants of health are discussed by Jessica Strong, Brandi Crowe, and Sarah Lawson, in "Female veterans: Navigating two identities." Using a case study, this article also illustrates how social workers in the field can best access resources and adapt interventions.

\section{Eras of Service}

Also contributing to the diversity of the veteran population are the conflicts in which veterans served. Each conflict speaks to a unique set of stressors and health concerns social workers will encounter. About 8 million veterans served during World War II from 1940 to 1945 (Elder 1987). Veterans served in a segregated military and were possibly drafted. While many African Americans felt conditions would improve following wartime service, many became more aware of segregation which extended to VA benefits including unemployment compensation, home loans, and the GI Bill (Onkst 1998). The Korean War, from 1950 to 1953 has been sometimes called the forgotten war (Fleming and Kaufman 1990; Keene 2011). The military was not prepared for the Korean winter, equipping service members with inadequate uniforms and summer boots. More than 5000 US troops were diagnosed with frostbite losing feet, hands, toes, and fingers to the elements (Cutter 2015). 
Veterans returning from Vietnam faced numerous stereotypes. Many were thought to be addicts or criminals or complicit in a war not supported by the American public (Pentland and Rothman 1982). Vietnam veterans faced a series of problems that were first denied by the medical community and the government. Researchers initially dismissed the condition of Vietnam veterans' mental health; believing that there was no cluster of symptoms veterans shared or that many problems could be attributed to pre-service stressors (Society for Science and the Public 1979). Veterans of the Vietnam War developed their own treatment groups for their PTSD symptoms. Known as rap groups, these sessions were organized by veterans in the early 1970 s to allow veterans to discuss the challenges they faced returning home and to develop a sense of meaning in their lives (Walker 1983).

Veterans of Operation Desert Storm Desert Shield served in the Persian Gulf region from 1991 to 1992 . Many veterans returned from deployment with symptoms of chronic fatigue, fibromyalgia, gastrointestinal conditions, and medically unexplained symptoms (e.g., memory loss, weight loss, joint pain, and skin conditions; National Academies of Science 2016). In our clinical experience, many veterans feel frustrated with the unknown nature of this condition. In a study of this cohort of veterans with medically unexplained symptoms, $65 \%$ believe the condition is permanent, $88 \%$ find that symptoms return after periods of remission, and $82 \%$ believe the condition requires medical treatment (Hunt et al. 2002). Unfortunately treatment protocols to treat Gulf War Illness lack scientific evidence. At the request of veterans' groups and the Institute of Medicine, there are many active protocols looking for effective treatments (Association of Military Surgeons of the United States 2017). In this special issue, Greenberg et al. discuss use of Problem Solving Therapy for Gulf War Veterans with Gulf War Illness. This adaptation of and evidence-based psychotherapy is a useful tool for clinicians working with Gulf War veterans.

Operation enduring freedom (OEF) lasted for 13 years and marked combat operations in Afghanistan from October 2001 through December 2014. Operation Iraqi freedom (OIF) is the war in Iraq which lasted from 2003 to 2011. Operation new dawn (OND) represents the continued deployment of troops to these regions from 2010 to the present. These all fall under the umbrella of the global war on terror (GWOT). Veterans of these wars benefited from improvements in battlefield medicine, surviving injuries that would have killed previous cohorts. This suggests higher rates of disability within OEF/OIF/OND veterans (Schwab et al. 2007).

It is also important to be mindful of the service of peacetime era veterans or those who served in conflicts that are less known (e.g., Grenada, Lebanon). In 2014, 14\% of all disability compensation payments from VA were made to peacetime era veterans (Burns et al. 2016). Atomic veterans, who served during the Cold War era in nuclear weapons including 210,000 service members who participated in 200 nuclear warhead tests (Hansen and Schriner 2005). Many veterans of this era have concerns about cancer rates and reproductive health as a consequence of exposure to radiation (Murphy et al. 1990).

\section{Access to Care}

Not all veterans meet criteria for VA care which includes a means test, demonstration of service connected disability, and type of discharge (US Department of Veterans Affairs 2018). Veterans with dishonorable discharges do not qualify for VA care. In fact, those who work with veterans who were discharged under dishonorable conditions may have more mental health needs than veterans with discharges under honorable conditions (Boscarino 2006). Veterans who are service connected for a disability incurred or exacerbated during military service receive compensation from the VA in the form of monetary compensation and access to health care. In the subsequent issue, Dennis Fried, Bart Holland, Marian Passannante, William Halperin, and Drew Helmer illustrate that those denied VA disability do not use VA health care and that they may in fact be more likely to use non-VA health care. This suggests a cohort of veterans who will encounter social workers in non-VA contexts who are likely in need of service.

\section{Stages of Psychosocial Development}

Social workers will also work with veterans at each adult stage of psychosocial development. Using the Eriksonian model, many veterans of the Gulf War and GWOT era would fall into Middle Adulthood, where the individual is focused on career consolidation and generativity. Here, the veteran would be focused on establishing their career as well as guiding the next generation. Failure to accomplish these developmental tasks can lead to difficulties in the next stage as well as distress in the current stage (Malone et al. 2016). Leaving the military may mean leaving a career and a clear identity. This may be especially challenging for disabled veterans who face a new career with a new set of abilities (Haynie and Shepherd 2011). This crossroads as well as the GI Bill bring many veterans to higher education to begin new careers (Barry et al. 2014). In fact, over 2.5 million OEF/ OIF/OND attend college using the GI Bill. As non-traditional students, veterans will encounter new challenges that set them apart from their civilian classmates (Borsari et al. 2017). In this issue, Leora Shudofsky and Michelle Ballan discuss Project for Return and Opportunity in Veterans 
Education, a program dedicated to serving veterans on college campuses.

If veterans are unable to meet basic needs, reaching these tasks for development are especially challenging. Veterans are over represented in the homeless population (US Department of Housing and Urban Development 2013). When compared to non-homeless veterans, homeless veterans are at greater risk for human immunodeficiency virus (HIV) as well as Hepatitis B and Hepatitis C (Noska et al. 2017), are less likely to fill psychotropic medication prescriptions for serious mental illness (Hermes and Rosenheck 2015), and are more likely to use the emergency department for health care (Gundlapalli et al. 2017). In "Moving beyond housing; Service implications for veterans entering permanent supportive housing," Harris, Winetrobe, Rhoades, Castro, and Wenzel analyze services utilized by homeless veterans. This article presents important information for providers working with this population and suggests that a variety of social work services are used by this population.

Also, part of the tasks of middle adulthood are caring for the next generation. In 2012, $44 \%$ of the military had children and in $2010,23 \%$ of the veteran population had at least one minor child who lived with them. Research suggests that veteran parents will struggle both with the reintegration process but also with parenting while coping with PTSD and depression. While research and programs address the needs of Active Duty military families, few have been developed for veteran populations (Creech et al. 2014). In this issue, Jessica Dodge, Midori Gonzalez, Maria Muzik, and Katherine Rosenblum present a mixed methods study on a parenting intervention for veterans who are fathers. It is hoped that the findings of this study can shape symptom management interventions for fathers as well as illuminate veterans' narratives on parenting.

\section{Conclusion}

In closing we hope that this issue not only speaks to the many challenges veterans face but also the tremendous resilience inherent to this population. Work with veterans is tremendously rewarding in part due to what we can learn about the power of resilience and posttraumatic growth. Research finds that among veterans who screen positive for PTSD, $72 \%$ report at least moderate levels of posttraumatic growth (Tsai et al. 2015). This posttraumatic growth is also found to be long lasting, with $60 \%$ of veterans reporting sustained moderate growth 2 years later (Tsai et al. 2016). This powerful reality of resilience is the story of many populations social workers work with. This literature specific to veterans may help draw more social workers to practice with a focus on resilience even if they are not working with veterans and their families. While this special issue could not cover all the issues facing veterans and social workers in practice today, we hope that it can provide a framework for future research, treatment, and education.

\section{References}

Association of Military Surgeons of the United States. (2017). Summary of featured study from the National Academies of Sciences, Engineering, and Medicine. Military Medicine, 182(1/2), 1449-1450.

Barry, A. E., Whiteman, S. D., \& Wadsworth, S. M. (2014). Student service members/veterans in higher education: A systematic review. Journal of Student Affairs Research and Practice, 51(1), $30-42$.

Beder, J., \& Postiglione, P. (2013). Social work in the Veterans Health Administration (VA) system: Rewards, challenges, roles and interventions. Social Work in Health Care, 52(5), 421-433.

Blosnich, J. R., Brown, G. R., Shipherd, J. C., Kauth, M., Piegari, R. I., \& Bossarte, R. M. (2013). Prevalence of gender identity disorder and suicide risk among transgender veterans utilizing Veterans Health Administration care. American Journal of Public Health, 103(10), e27-e32.

Borsari, B., Yurasek, A., Miller, M. B., Murphy, J. G., McDevitt-Murphy, M. E., Martens, M. P., ... Carey, K. B. (2017). Student service members/veterans on campus: Challenges for reintegration. American Journal of Orthopsychiatry, 87(2), 166.

Boscarino, J. A. (2006). Posttraumatic stress disorder and mortality among US Army veterans 30 years after military service. Annals of Epidemiology, 16(4), 248-256.

Burns, S. K., Guerrera, K. M., Hunter, D. E., \& Rieksts, B. Q. (2016). Trends in VBA disability compensation spending. Institute for Defense Analyses: Alexandria, VA.

Creech, S. K., Hadley, W., \& Borsari, B. (2014). The impact of military deployment and reintegration on children and parenting: A systematic review. Professional Psychology: Research and Practice, $45(6), 452$.

Cutter, L. (2015). Extreme weather conditions: Military medicine responds to a Korean War winter. Military Medicine, 180(9), 1017-1018.

Elder, G. H. (1987). War mobilization and the life course: A cohort of World War II veterans. Sociological Forum, 2(3), 449-472.

Fleming, D. B., \& Kaufman, B. I. (1990). The forgotten war: Korea. Social Education, 54(1), 35-38.

Gundlapalli, A. V., Redd, A., Bolton, D., Vanneman, M. E., Carter, M. E., Johnson, E., ... O'Toole, T. P. (2017). Patient-aligned care team engagement to connect Veterans experiencing homelessness with appropriate health care. Medical Care, 55, S104-S110.

Hansen, D., \& Schriner, C. (2005). Unanswered questions: The legacy of atomic veterans. Health Physics, 89(2), 155-163.

Haynie, J. M., \& Shepherd, D. (2011). Toward a theory of discontinuous career transition: Investigating career transitions necessitated by traumatic life events. Journal of Applied Psychology, 96(3), 501.

Hermes, E. D., \& Rosenheck, R. A. (2015). Implementing computerbased psychotherapy among veterans in outpatient treatment for substance use disorders. Psychiatric Services, 67(2), 176-183.

Hunt, S. C., Richardson, R. D., \& Engel, C. C. Jr. (2002). Clinical management of Gulf War veterans with medically unexplained physical symptoms. Military Medicine, 167(5), 414-420.

Hynes, D. M., Koelling, K., Stroupe, K., Arnold, N., Mallin, K., Sohn, M. W., ... Kok, L. (2007). Veterans' access to and use of Medicare and Veterans Affairs health care. Medical Care, 45(3), 214-223. 
Keene, J. (2011). Lost to public commemoration: American veterans of the" forgotten" korean war. Journal of Social History, 44(4), $1095-1113$.

Kizer, K. W. (2012). Veterans and the affordable care act. JAMA, 307(8), 789-790.

Koblinsky, S. A., Leslie, L. A., \& Cook, E. T. (2014). Treating behavioral health conditions of OEF/OIF veterans and their families: A state needs assessment of civilian providers. Military Behavioral Health, 2(2), 162-172.

Malone, J. C., Liu, S. R., Vaillant, G. E., Rentz, D. M., \& Waldinger, R. J. (2016). Midlife Eriksonian psychosocial development: Setting the stage for late-life cognitive and emotional health. Developmental Psychology, 52(3), 496.

Murphy, B. C., Ellis, P., \& Greenberg, S. (1990). Atomic veterans and their families: Responses to radiation exposure. American Journal of Orthopsychiatry, 60(3), 418.

National Academies of Sciences, Engineering, and Medicine. (2016). Gulf War and health: Volume 10: Update of serving in the Gulf War, 2016. Washington, DC: The National Academies Press.

National Center for Veterans Analysis and Statistics. (2016). Profile of veterans 2014: Data from the American Community Survey. Washington, DC: US Department of Veterans Affairs.

Noska, A. J., Belperio, P. S., Loomis, T. P., O’toole, T. P., \& Backus, L. I. (2017). Prevalence of human immunodeficiency virus, Hepatitis $\mathrm{C}$ virus, and Hepatitis B virus among homeless and non-homeless United States veterans. Clinical Infectious Diseases, 65(2), 252-258.

Oddone, E. Z., Petersen, L. A., Weinberger, M., Freedman, J., \& Kressin, N. R. (2002). Contribution of the Veterans Health Administration in understanding racial disparities in access and utilization of health care: A spirit of inquiry. Medical Care, 40(1), I-3.

Onkst, D. H. (1998). "First a negro... incidentally a veteran": Black World War Two veterans and the GI Bill of rights in the Deep South, 1944-1948. Journal of Social History, 31(3), 517-543.

Pentland, B., \& Rothman, G. (1982). The incarcerated Vietnam-service veteran: Stereotypes and realities. Journal of Correctional Education, 33(1), 10-14.

Saha, S., Freeman, M., Toure, J., Tippens, K. M., Weeks, C., \& Ibrahim, S. (2008). Racial and ethnic disparities in the VA health care system: A systematic review. Journal of General Internal Medicine, 23(5), 654-671.

Schwab, K. A., Warden, D., Lux, W. E., Shupenko, L. A., \& Zitnay, G. (2007). Defense and veterans brain injury center: Peacetime and wartime missions. Journal of Rehabilitation Research \& Development, 44(7), xiii-xiii.

Society for Science \& the Public. (1979). What is 'post vietnam syndrome'? Science News, 116(13), 213.

Tsai, J., El-Gabalawy, R., Sledge, W. H., Southwick, S. M., \& Pietrzak, R. H. (2015). Post-traumatic growth among veterans in the USA: Results from the National Health and Resilience in Veterans Study. Psychological Medicine, 45(1), 165-179.

Tsai, J., Sippel, L. M., Mota, N., Southwick, S. M., \& Pietrzak, R. H. (2016). Longitudinal course of posttraumatic growth among US Military Veterans: Results from the National Health and Resilience in Veterans Study. Depression and Anxiety, 33(1), 9-18.

US Department of Housing and Urban Development. (2013). The 2013 annual homeless assessment report to Congress. Washington, DC: HUD, Office of Community Planning and Development.

US Department of Veterans Affairs. (2018). Health benefits: Veterans eligibility. Washington, DC: US Department of Veterans Affairs. Retrieved May 1, 2018, from https://www.va.gov/healthbenefits/ apply/veterans.asp.

Walker, J. I. (1983). Comparison of "rap" groups with traditional group therapy in the treatment of Vietnam combat veterans. Group, 7(2), $48-57$.

Whitehead, A. M., Czarnogorski, M., Wright, S. M., Hayes, P. M., \& Haskell, S. G. (2014). Improving trends in gender disparities in the Department of Veterans Affairs: 2008-2013. American Journal of Public Health, 104(S4), S529-S531.

Katharine Bloeser is a licensed clinical social worker in Washington, DC and is currently an assistant professor at the Silberman School of Social Work at Hunter College of the City University of New York.

Kathleen Ray is a licensed clinical social worker in New Jersey and is currently an assistant professor at Ramapo College of New Jersey School of Social Science and Human Services. 